\title{
The Role of Neurotrophins in the Seasonal-Like Growth of the Avian Song Control System
}

\author{
Anne Marie Wissman ${ }^{1}$ and Eliot A. Brenowitz ${ }^{2,3}$ \\ ${ }^{1}$ Graduate Program in Neurobiology and Behavior, and Departments of 2Zoology and ${ }^{3}$ Psychology, University of Washington, Seattle, Washington 98195
}

The avian song control system undergoes pronounced seasonal plasticity in response to photoperiod and hormonal cues. The action of testosterone (T) and its metabolites in the song nucleus HVC is both necessary and sufficient to promote breeding season-like growth of its efferent nuclei RA (robust nucleus of the arcopallium) and Area X, suggesting that HVC may release a trophic factor such as brainderived neurotrophic factor (BDNF) into RA and X. BDNF is involved in many forms of adult neural plasticity in other systems and is present in the avian song system. We used a combination of in situ hybridization and intracerebral infusions to test whether BDNF plays a role in the seasonal-like growth of the song system in adult male white-crowned sparrows. BDNF mRNA levels increased in HVC in response to breeding conditions, and BDNF infusion into RA was sufficient to promote breeding-like changes in somatic area and neuronal density. Expression of the mRNA for the Trk B receptor of BDNF, however, did not vary with seasonal conditions in either HVC or RA. Local blockade of BDNF activity in RA via infusion of Trk-Fc fusion proteins inhibited the response to breeding conditions. Our results indicate that BDNF is sufficient to promote the seasonal plasticity in somatic area and cell density in RA, although NT-3 may also contribute to this process, and suggest that HVC may be a presynaptic source of increased levels of BDNF in RA of breeding-condition birds.

\section{Introduction}

Seasonal plasticity of the avian song system is a model for understanding general mechanisms of adult neural plasticity and the effects of hormones on the brain. Steroid hormones have a robust influence on neuronal morphology and physiology, both via direct action within a song nucleus and via transsynaptic trophic effects (Brenowitz, 2004; Meitzen et al., 2007b). The mechanism underlying these transsynaptic effects is unknown, however.

The song system is a network of discrete nuclei that mediate song learning and production (supplemental Fig. S1, available at www.jneurosci.org as supplemental material). Song nuclei, including the forebrain areas HVC (used as a proper name), the robust nucleus of the arcopallium (RA), and Area X, show striking morphological plasticity in seasonally breeding birds (reviewed by Brenowitz, 2004). Long days (LDs) and increased testosterone (T) levels, typical of breeding birds, promote growth of song nuclei. $\mathrm{T}$ acts on androgen receptors (AR), and also on estrogen receptors (ER) via aromatization to $17-\beta$ estradiol $\left(\mathrm{E}_{2}\right)$, on HVC to increase its volume and neuron number, and volume and neuronal somatic area and density (but not neuron number) in RA and Area X (Brenowitz, 2004). Spontaneous electrical ac-

\footnotetext{
Received Jan. 16, 2009; accepted Feb. 27, 2009.

This work was supported by a Howard Hughes Medical Institute Predoctoral Fellowship (to A.M.W.) and National Institutes of Health Grants MH53032 (to E.A.B.) and P30DC04661. We thank Karin Lent for her technical assistance, Xiao-Ching Li for her gift of the BDNF cDNA probe, Arthur Arnold for his gift of the TrkB cDNA probe, and Stanley Wiegand of Regeneron Pharmaceuticals for gifts of recombinant BDNF and fusion Abs. We also thank Elena Chartoff, Olivia Birmingham-McDonough, and Jeremy Smith for their technical advice, and we are grateful to Daniel Dorsa, Edwin Rubel, and Robert Steiner for the use of facilities and equipment.

Correspondence should be addressed to Dr. Anne Marie Wissman at her present address: Department of Neurobiology and Physiology, Northwestern University, 2205 Tech Drive, Evanston, IL 60208. E-mail: a-wissman@northwestern.edu.

DOI:10.1523/JNEUROSCI.0638-09.2009

Copyright $\odot 2009$ Society for Neuroscience $\quad$ 0270-6474/09/296461-11\$15.00/0
}

tivity in RA also increases (Meitzen et al., 2007a), as does song stereotypy (Brenowitz, 2004).

HVC exerts a transsynaptic influence on its efferent nuclei RA and X (reviewed by Brenowitz, 2004; Meitzen et al., 2007b). HVC responds directly to $\mathrm{T}$ or its metabolites and provides permissive or trophic support of growth to its efferent targets. Such support might include an anterogradely transported growth factor such as brain-derived neurotrophic factor (BDNF).

The neurotrophin family of proteins, including BDNF, nerve growth factor (NGF), NT-3, and NT-4, bind with high affinity to Trk receptors to initiate several signaling cascades with pronounced effects on neural plasticity in the developing and adult brain (Patapoutian and Reichardt, 2001). BDNF is released primarily in an activity-dependent manner (Kojima et al., 2001; Lessmann et al., 2003; Thomas and Davies, 2005) and is linked to activity-dependent and hormone-dependent changes in synapse formation/efficacy, as well as neuronal morphology and survival (Binder and Scharfman, 2004). Although most studies of neurotrophins involve retrograde transport and release mechanisms (Zweifel et al., 2005), the effects of neurotrophins are often mediated by anterograde transport and release to target cells (von Bartheld et al., 2001). Thus, BDNF is a likely candidate for mediating transsynaptic seasonal changes in the song system, either alone or in conjunction with other growth factors.

Neurotrophins and their receptors are present in song nuclei and influence both the neural circuitry and song behavior. BDNF and its cognate receptor TrkB and NT-3 are found in HVC, RA, and Area X in canaries and/or zebra finches (Rasika, 1998; Wade, 2000; Quagliano and Bottjer, 2004; Chen et al., 2005). BDNF influences song circuit development (Johnson et al., 1997) and neurogenesis in adult HVC (Rasika et al., 1999). Systemic $\mathrm{E}_{2}$ treatment upregulates BDNF mRNA in juvenile zebra finches 
(Dittrich et al., 1999), and singing increases its expression in RAprojecting HVC neurons ( $\mathrm{Li}$ et al., 2000). Little is known about the actions of the other neurotrophins in the song system.

Anterograde transport of BDNF from HVC to RA and X could contribute to the transsynaptic effects of $\mathrm{T}$ in seasonally breeding birds. We focused on the effects of BDNF in RA because the irregular shape and large size of Area X make it less amenable than $\mathrm{RA}$ to intracerebral infusions that penetrate the entire nucleus. Here we show that BDNF expression in HVC is regulated by seasonal-like cues, and that BDNF activity induces growth of RA. NT-3 may also play a role in the growth of RA in response to seasonal cues. This is the first study to demonstrate the dependence of adult song system plasticity on neurotrophins.

\section{Materials and Methods}

All protocols used in this experiment were approved by the University of Washington Institutional Animal Care and Use Committee and were in accordance with the NIH Guidelines for the Care and Use of Laboratory Animals.

We captured adult male Gambel's white-crowned sparrows (GWCS) in eastern Washington state during their postbreeding season migration. We housed birds indoors in group aviaries for a minimum of 12 weeks on a short day (SD; $8 \mathrm{~h}$ of light) photoperiod to ensure that their reproductive systems were regressed but sensitive to photoperiod and hormonal cues typical of the breeding season (i.e., photosensitive).

Experiment 1. BDNF and TrkB in situ hybridization: photoperiod shift and testosterone treatment. The nature and magnitude of the plasticity seen in wild birds captured in different seasons can be replicated in the laboratory by mimicking the increased day length and T levels that are seen in breeding-condition birds in the wild (Smith et al., 1997b,c; Tramontin, 2000). At the start of the experiment, we placed birds in one of four groups ( $n=6$ each group). We implanted birds in the first group with an empty subcutaneous $12 \mathrm{~mm}$ length of SILASTIC tubing (1.47 $\mathrm{mm}$ inner diameter; $1.96 \mathrm{~mm}$ outer diameter; VWR) and maintained them on SD for $7 \mathrm{~d}$ (SD group). We implanted birds in the second group with SILASTIC tubing filled with crystalline $\mathrm{T}$ (12 $\mathrm{mm}$ length; washed in ethanol and soaked in saline overnight; Steraloids), shifted them overnight to an LD (20 h of light) photoperiod, and maintained them on LD for $3 \mathrm{~d}$ (LD+T $3 \mathrm{~d}$ group). We implanted birds in the third group with $\mathrm{T}$, shifted them overnight to LD, and maintained them on LD for $7 \mathrm{~d}$ (LD+T $7 \mathrm{~d}$ group). The $\mathrm{T}$ implants are necessary because captive sparrows exposed in the laboratory to LD photoperiod alone do not achieve plasma T levels typical of wild breeding birds (Smith et al., 1995). To test the effects of photoperiod in the absence of circulating $\mathrm{T}$, we castrated each male in the fourth group, allowed it to recover for $7 \mathrm{~d}$, shifted it to LD, and implanted each bird with an empty SILASTIC tube (LD-gonx group). These birds were maintained on LD for $7 \mathrm{~d}$. We did not include a $\mathrm{SD}+\mathrm{T}$ group, because a previous study showed no difference in morphological parameters between $\mathrm{LD}+\mathrm{T}$ and $\mathrm{SD}+\mathrm{T}$ groups, whereas $\mathrm{LD}$ alone had a small effect (Smith et al., 1997b). Birds in each group were housed in individual cages in the same room, with ad libitum access to food and water.

These procedures were replicated for Experiment $1 \mathrm{~b}$ below, with the omission of the LD-gonx treatment group.

Experiment 1a: Song recording. Birds were monitored for song behavior for $1 \mathrm{~h}$ after subjective dawn (lights on) each day of treatment and also for $1 \mathrm{~h}$ immediately before being killed. Song was recorded using tie-clip microphones attached to individual cages connected to a Sony TCD-5M cassette recorder. Recordings were digitized via Syrinx software (J. Burt) and songs were counted using customized software (Meitzen et al., 2007b).

Experiment 1: Histological procedures. Birds were killed by decapitation and trunk blood samples were collected to measure plasma T levels. Brains were removed, rinsed in cold PBS, dipped in M1 Embedding Compound (Shandon), frozen on dry ice, and stored at $-80^{\circ} \mathrm{C}$ until sectioning. We sectioned the brains coronally on a cryostat at $12 \mu \mathrm{m}$, thaw-mounted sections onto Superfrost slides in four sets, and stored the slides in air-tight boxes at $-80^{\circ} \mathrm{C}$ until in situ hybridization.
In preparation for hybridization, sections were fixed in $4 \%$ paraformaldehyde, $\mathrm{pH}$ 7.4, washed in PBS, acetylated in acetic anhydride, and delipidized in chloroform.

Experiment 1a: BDNF in situ hybridization and quantification. We used a 600-bp cDNA probe against zebra finch BDNF (a gift from Dr. X.-C. Li, Louisiana State University, New Orleans, LA) (Li et al., 2000a). After linearizing the plasmids, we transcribed sense and antisense probes labeled with ${ }^{35} \mathrm{~S}$-UTP (PerkinElmer) and purified them via phenol/chloroform extraction. We hybridized the sections for $18 \mathrm{~h}$ at $65^{\circ} \mathrm{C}$ in hybridization buffer (50\% formamide/10\% dextran sulfate/1\% Denhardt's solution/0.3M NaCl/100 mm DTT/10 mm Tris/1 mm EDTA/0.65 $\mathrm{mg} / \mathrm{ml}$ yeast tRNA) with $0.75 \mathrm{pmol} / \mathrm{ml}$ radiolabeled probe. We washed the sections in a graded series of low- and high-stringency washes, from $2 \times \mathrm{SSC}$ at room temperature to $0.1 \times \mathrm{SSC}$ at $65^{\circ} \mathrm{C}$, dried them, and exposed them to film for $4 \mathrm{~d}$. We then dipped the slides in NTB-2 emulsion (Kodak), exposed them at room temperature for 6 weeks, developed them in Kodak D-19 developer, and fixed them. We lightly counterstained sections with cresyl violet. An adjacent set of sections was fixed in $4 \%$ paraformaldehyde and stained more darkly with thionin for clearer visualization of the song nuclei.

We randomly chose three HVC-containing or RA-containing sections from each bird for analysis. For each section, we randomly chose a side to analyze and determined the borders of the song nuclei based on the cresyl violet stain and the adjacent thionin-stained sections. We placed a grid over each nucleus and chose three boxes $(52 \times 50 \mu \mathrm{m})$ within and three boxes over adjacent tissue outside the nucleus for grain-counting. The first box in each nucleus was chosen randomly within one-third of the nucleus, and the next two were placed a constant distance away to ensure even distribution of sampling across the full medial-lateral and dorsalventral extent of the region of interest. At $100 \times$ under bright-field optics, we used a customized macro in NIH Image (W. Rasband, National Institutes of Health, Bethesda, MD) to calibrate the average grain size, optimize the grain-detection threshold, and count silver grains in each sampling box. For each section, we also collected three measurements of background grains in an adjacent area of the slide with no tissue. The within-nucleus, outside-nucleus, and no-tissue background grain density (grains/area) measurements for each section were collected under the same light intensity and threshold parameters. For each nucleus, we subtracted the average no-tissue background grain density both from the average within-nucleus density and from the average outside-nucleus density and then expressed the adjusted data as a ratio of the grain density in the song nucleus over the grain density in the surrounding tissue. We observed some clustering of grains over heavily labeled cells, but the amount of scatter and the condition of the tissue did not allow us to do a rigorous cellular analysis of grain number.

Experiment 1b: TrkB in situ hybridization and quantification. We used a 2.3-kbp cDNA sequence that partially encodes zebra finch TrkB (a gift from Dr. A. Arnold, University of California, Los Angeles, Los Angeles, CA) (Chen et al., 2005). We amplified a 425-bp region of the cDNA near the $\mathrm{N}$ terminus of the kinase domain that is specific to a full-length active form of TrkB, using as primers 5' -TTGGCCAAGGCATCTCCAGT-3' and $5^{\prime}$-TTGTGGTGGGCAAACTGGAG-3'. We cloned our fragment into the PCR4-TOPO plasmid (Invitrogen).

After linearizing the plasmid, we transcribed sense and antisense probes labeled with ${ }^{33} \mathrm{P}$-UTP (PerkinElmer) and purified them with NucAway spin columns (Ambion). We hybridized the sections for $16 \mathrm{~h}$ at $55^{\circ} \mathrm{C}$ in hybridization buffer $(62.5 \%$ formamide $/ 12.5 \%$ dextran sulfate/ $0.375 \mathrm{~m} \mathrm{NaCl} / 10 \mathrm{~mm}$ Tris/1 mm EDTA/0.02\% BSA/0.02\% Ficoll/0.02\% polyvinylpyrrolidone $/ 1.9 \mathrm{mg} / \mathrm{ml}$ tRNA) with $0.05 \mathrm{pmol} / \mathrm{ml}$ radiolabeled probe. After washing the slides in $2 \times$ SSC at room temperature, we treated them with RNase for $30 \mathrm{~min}$. We washed the sections in a graded series of low- and high-stringency washes, from $2 \times$ SSC at room temperature to $0.1 \times \mathrm{SSC}$ at $65^{\circ} \mathrm{C}$, dried them, and dipped the slides in Kodak NTB-3 emulsion, exposed them at room temperature for 1 week, developed them in Kodak D-19 developer, and fixed them. As in Experiment la, we lightly counterstained sections with cresyl violet and stained an adjacent set of sections more darkly with thionin for clearer visualization of the song nuclei.

We randomly chose three RA-containing sections from each bird for 
A
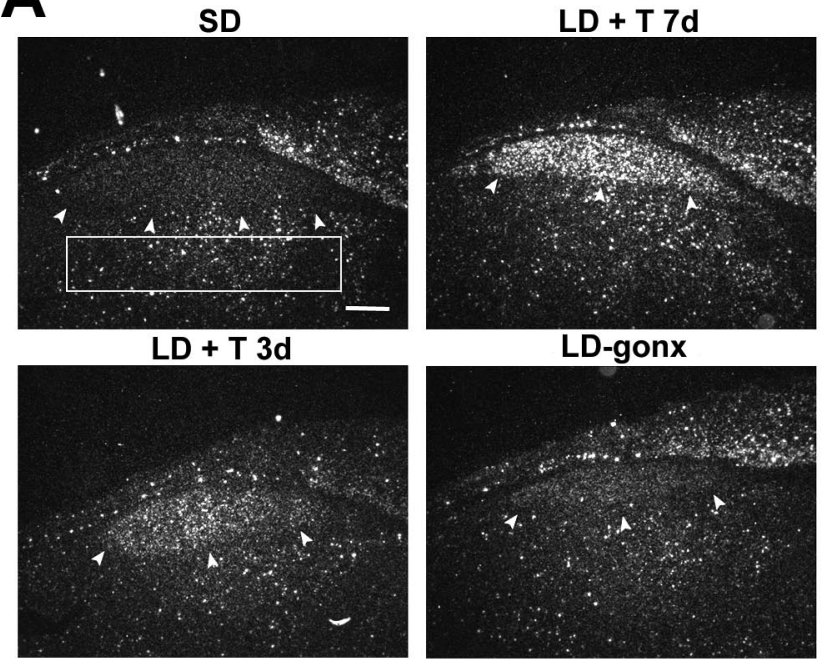

C

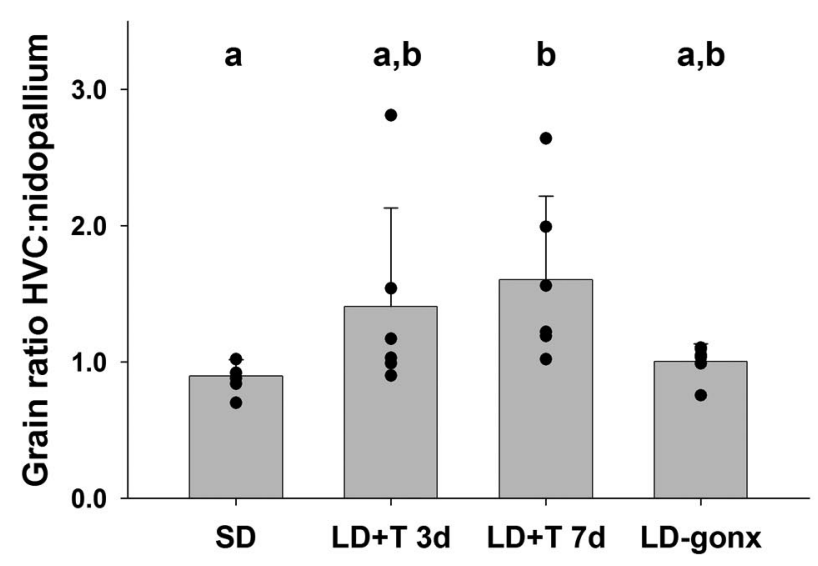

B
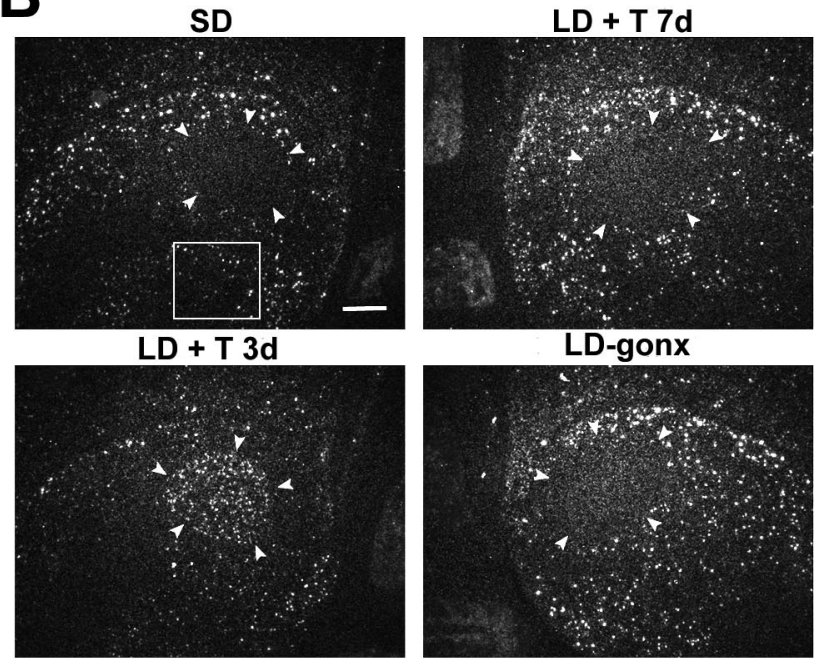

LD-gonx

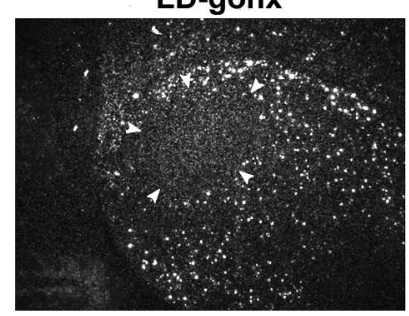

D

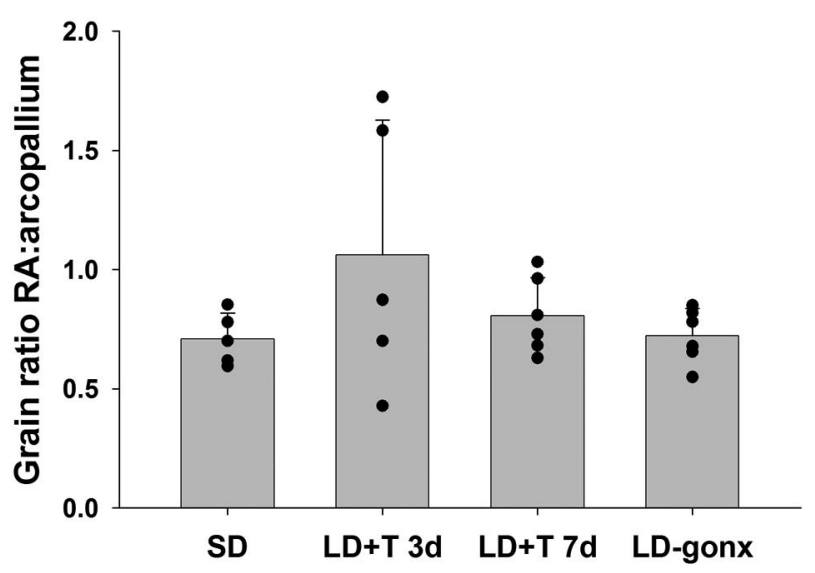

Figure 1. Dark-field photomicrographs of in situ hybridization showing BDNF mRNA expression in HVC $(\boldsymbol{A})$ and RA (B) of birds in the four treatment groups. Arrows delineate the borders of the song nuclei. Boxes indicate area from which pallial measurements were taken. Scale bars, $300 \mu \mathrm{m}$. Quantitative analysis of BDNF mRNA expression in HVC (C) and RA ( $\boldsymbol{D}$ ). Data are expressed as a ratio of the grain density within the song nucleus versus the surrounding pallial region. Bars are group means \pm SEM, and each point represents one bird. Letters above bars represent statistically different groups (Tukey's HSD $p<0.05$ ).

analysis. Analysis of TrkB in situ tissue was performed using a different microscope and computer system than the analysis of BDNF in situ tissue. For each section, we randomly chose a side to analyze and determined the borders of RA based on the cresyl violet stain and the adjacent thionin-stained sections. We used a customized macro in NIH Image (developed at the National Institutes of Health and available at http:// rsb.info.nih.gov/nih-image/) to randomly place three boxes $(280 \times 210$ $\mu \mathrm{m})$ within and three boxes outside RA for sampling. At $40 \times$ power under dark-field optics, we used NIH Image to optimize the graindetection threshold and measured the percentage area occupied by thresholded pixels. We collected within-nucleus, outside-nucleus, and no-tissue background grain measurements for each section as described above. As in Experiment 1a, we observed some clustering of grains over heavily labeled cells, but the amount of scatter and the condition of the tissue were such that we could not do a cellular analysis of grain number.

Experiment 1. Radioimmunoassay for T levels. Blood samples $(\sim 400$ $\mu \mathrm{l})$ were collected from trunk blood at decapitation into heparinized microcentrifuge tubes. Each blood sample was immediately centrifuged, and the plasma was removed and stored at $20^{\circ} \mathrm{C}$ until assay. The Coat-aCount Total Testosterone radioimmunoassay kit (Diagnostic Products) was used to measure plasma concentrations of T. This assay has been validated for measurement of plasma $\mathrm{T}$ levels in birds (Tramontin et al., 2001). The minimum detectable plasma T concentration was $0.2 \mathrm{ng} / \mathrm{ml}$; samples with undetectable levels were treated as having concentrations at the detection limit for statistical purposes. Interassay variability was $3.63 \pm 0.93 \%$.

Experiment 2: BDNF and Trk-Fc infusion into RA: surgical procedures. We anesthetized birds with isoflurane and placed them in a stereotaxic apparatus. We made an incision in the scalp and placed a small hole in the skull over RA. A 28 gauge cannula (Alzet Brain Infusion Kit II) was implanted dorsocaudally to RA on one side of the brain (anteroposterior, $2.25 \mathrm{~mm}$; mediolateral, 3.35; depth, $2.35 \mathrm{~mm}$ ) and held in place with dental cement. We left the other side of the brain intact to serve as a within-subjects control. Although there is ample evidence in songbirds for laterality in the peripheral control of song production, there is no evidence for laterality in the morphology of forebrain song nuclei (Suthers, 1997), and the lack of direct connectivity between song nuclei across hemispheres makes unilateral approaches powerful in this system (Wild, 1997). An osmotic pump (Alzet 1002) containing either human recombinant $\operatorname{BDNF}(0.67,1.0$, or $1.5 \mathrm{mg} / \mathrm{ml}$; a gift from Regeneron) or NGF $(1.5 \mathrm{mg} / \mathrm{ml}$; Millipore Bioscience Research Reagents) in $100 \mu$ l of vehicle (PBS), or vehicle alone, was implanted under the skin of the back and connected to the cannula with tubing. NGF was used as an additional control for general effects of neurotrophic factors, such as binding to the p75 receptor; this strategy is common in neurotrophin studies (Galuske et al., 1999; Lu et al., 2004). After surgery, we housed birds in individual 
Table 1. Grain density ratios for BDNF $m$ RNA in HVC and RA and for TrkB mRNA in RA (mean \pm SEM)

\begin{tabular}{|c|c|c|c|c|c|c|}
\hline & \multicolumn{4}{|l|}{ Treatment } & \multicolumn{2}{|c|}{$\begin{array}{l}\text { Kruskal-Wallis one-way } \\
\text { ANOVA on ranks }\end{array}$} \\
\hline & SD & $L D+T 3 d$ & $L D+T 7 d$ & LD-gonx & $H$ & $p$ \\
\hline \multicolumn{7}{|l|}{ BDNF grain density ratio } \\
\hline HVC:nidopallium & $0.90 \pm 0.049^{a}$ & $1.60 \pm 0.25^{a, b}$ & $1.41 \pm 0.29^{b}$ & $1.00 \pm 0.05^{a, b}$ & 10.91 & 0.012 \\
\hline RA:arcopallium & $0.71 \pm 0.049$ & $1.06 \pm 0.25$ & $0.81 \pm 0.065$ & $0.721 \pm 0.047$ & 2.14 & 0.54 \\
\hline \multicolumn{7}{|l|}{ TrkB grain density ratio } \\
\hline RA:arcopallium & $0.80 \pm 0.054$ & $0.99 \pm 0.12$ & $1.02 \pm 0.09$ & n/a & 3.80 & 0.15 \\
\hline
\end{tabular}

$\mathrm{n} / \mathrm{a}$, Not applicable.

${ }^{a, b}$ Within rows, values with different superscripts differ significantly from each other, Tukey's HSD, $p<0.05$.

cages and monitored weight and general condition daily. We kept birds on SD for the remainder of the experiment to avoid any stimulating effects of LD photoperiod.

Surgical procedures for Experiment $2 \mathrm{~b}$ were identical to Experiment $2 a$, with the exception that instead of neurotrophins, we infused fusion proteins consisting of the extracellular portion of the TrkB or TrkC receptor fused to the Fc portion of the human IgG molecule. These proteins bind to endogenous neurotrophins and interfere with their biological activity (Shelton et al., 1995). Pilot studies showed that infusion of TrkB fusion antibodies (Abs) alone did not block the $\mathrm{LD}+\mathrm{T}$ induced growth of RA neurons. Given Bottjer and Quagliano's observation that NT-3 is expressed in HVC in juvenile zebra finches (Quagliano and Bottjer, 2004) and previous studies showing coexpression of TrkB and TrkC in brain areas across phyla (reviewed by von Bartheld and Fritzsch, 2006), we therefore also infused TrkC fusion Abs alone or with TrkB fusion Abs to determine whether a combination of neurotrophins might be involved. An osmotic pump (Alzet 1002; Durect) containing $100 \mu \mathrm{l}$ of vehicle (PBS; $n=3)$, TrkB-Fc alone $(n=3)$, TrkC-Fc alone $(n=3)$, or a 1:1 combination of TrkB-Fc and TrkC-Fc (a gift from Regeneron; $n=9$ ) was implanted under the skin of the back and connected to the cannula with tubing. Pilot studies determined the optimal concentration of each fusion protein to be $0.5 \mathrm{mg} / \mathrm{ml}$. During the same surgery session, we implanted birds with a subcutaneous 12 -mm-SILASTIC implant filled with crystalline $\mathrm{T}$, housed them in individual cages and shifted them overnight to an LD photoperiod ( $16 \mathrm{~h}$ of light) for the duration of the experiment. We monitored bird weight and general condition daily.

Experiment 2: Histological procedures. Fourteen days after surgery, we anesthetized birds deeply with metofane and perfused them transcardially with heparinized saline followed by $4 \%$ paraformaldehyde. Brains were removed and postfixed overnight in $4 \%$ paraformaldehyde, embedded in gelatin, cryoprotected in a $20 \%$ sucrose $/ 10 \%$ formalin solution, and sectioned coronally at $40 \mu \mathrm{m}$ on a freezing microtome. We mounted every third section onto slides and stained them for Nissl with thionin.

To confirm that the infused proteins reached RA and to measure the extent of spread from the cannula tip, we processed alternate sections containing HVC, RA, and the region of cannula penetration for immunolabeling for the infused antigen. For Experiment 2a, we labeled sections with a monoclonal $\mathrm{Ab}$ against human recombinant BDNF (hrBDNF; GF35 L; Calbiochem). This Ab does not label endogenous BDNF in GWCS tissue under these protocols, and we did not see labeling in the hemisphere contralateral to the cannula or in vehicle control tissue (supplemental Fig. S4b, available at www.jneurosci.org as supplemental material). Sections were rinsed in $0.1 \mathrm{M}$ PBS, treated with $1 \% \mathrm{H}_{2} \mathrm{O}_{2}$ in PBS to quench endogenous peroxidases, rinsed in PBS with $0.1 \%$ Triton $\mathrm{X}-100$ (PBS-TX), blocked in 10\% normal horse serum (NHS), and incubated overnight at room temperature with the BDNF Ab (1:1000 with 5\% NHS in PBS-TX). Sections were rinsed in PBS-TX and incubated for $1 \mathrm{~h}$ with biotinylated horse anti-mouse secondary (1/200 in PBS-TX; Vector Laboratories). We washed sections in PBS, incubated in an avidin-biotin complex (Vector ABC Standard kit), rinsed in $0.1 \mathrm{~m}$ Tris buffer (TB) and visualized with diaminobenzidine chromagen $(0.25 \mathrm{mg} / \mathrm{ml}$ in $\mathrm{TB}$; Sigma). For brains infused with NGF, we labeled sections with a polyclonal Ab against human NGF (H-20; Santa Cruz Biotechnology). The procedure was identical to the BDNF staining, except for the primary $\mathrm{Ab}$, which was used at 1:250. For Experiment 2b, we labeled sections with a biotinylated $\mathrm{Ab}$ against the human $\operatorname{IgG}$ molecule, which labels the $\mathrm{Fc}$ portion of the fusion proteins. We did not see labeling in uninfused or vehicle control tissue (supplemental Fig. S4d, available at www. jneurosci.org as supplemental material). As above, sections were rinsed in PBS, treated with $1 \% \mathrm{H}_{2} \mathrm{O}_{2}$ in PBS, rinsed in PBS-TX, blocked in $10 \%$ NHS, and incubated overnight with the human IgG Ab (1:200 with 5\% NHS in PBS). We washed sections in PBS, incubated in ABC, rinsed in $\mathrm{TB}$, and visualized with diaminobenzidine.

In addition to the immunostaining, we also tested for the patency of the cannulae after removing them from the brain by cutting the tubing leading from the osmotic pumps, applying a small amount of pressure to the cut ends of the tubing with a syringe and determining whether the remaining fluid in the tubing flowed ad libitum from the ends of the cannulae. We then examined the fluid reservoirs of the pumps to ensure that most of the contents had been discharged. Lack of patency or an excess of remaining fluid were combined with the results of the immunostaining to identify birds in which obstruction of the cannula may have compromised the infusion experiment. Data from these birds were removed from the analyses.

We measured the distance from the cannula to the nearest border of RA in Nissl-stained tissue. Pilot studies showed that infusion of fusion proteins further than $300 \mu \mathrm{m}$ from RA was not effective, regardless of the presence of immunolabeling in RA, so we only included data from birds in which the cannula was within $300 \mu \mathrm{m}$ of RA. We did not include data from birds in which the cannula was placed close enough to damage RA itself.

Experiment 2: Brain morphometry. We traced the perimeters of HVC and RA on each side of the brain based on Nissl staining from low-power images of the nuclei in each section. We calculated areas in NIH Image and estimated the volume of each nucleus by summing the estimated volumes of the sections between using the formula for a cone frustrum (Smith et al., 1997a). The areas and densities of neuronal somata in HVC and RA were analyzed using a random systematic sampling scheme that yields estimates of neuronal size and density that do not differ from those obtained using the stereological optical dissector method (Tramontin et al., 1998). We randomly placed $20-25$ boxes in four to five sections throughout each side of HVC and RA. Boxes in HVC measured 45.9 by $22.9 \mu \mathrm{m}$, and boxes in RA measured 69 by $45.8 \mu \mathrm{m}$. In each side of RA, we measured and counted at least 100 cells, and in each side of HVC, we measured and counted at least 150 cells; previous studies show that these sample sizes encompass the full range of variability in somal area and neuronal density (Brenowitz et al., 1995; Tramontin et al., 1998). Neurons were distinguished from glia by having one round nucleolus, a well-defined nuclear envelope, nongranular cytoplasm, and/or an obvious axon hillock (Goldman and Nottebohm, 1983; Smith et al., 1995; Smith et al., 1997a,b; Tramontin et al., 1998). We estimated cell density by dividing the number of cells counted in each sampling box by the volume of the box $\left(1.27 \times 10^{-4} \mathrm{~mm}^{3}\right)$ and averaged across boxes for each bird.

Statistics. For Experiment 1, the data were not normally distributed, and we therefore performed Kruskal-Wallis one-way ANOVAs on ranks on the grain density ratios across groups within HVC and within RA. We used Tukey's HSD test for post hoc multiple comparisons when the main effect was significant. We also performed linear regression analyses on the grain densities in $\mathrm{HVC}$ as a function of plasma T concentration and song rate.

Descending projections from HVC in the song system are largely unilateral, and there is no direct connection between hemispheres at the telencephalic level (Schmidt et al., 2004). We therefore compared the 

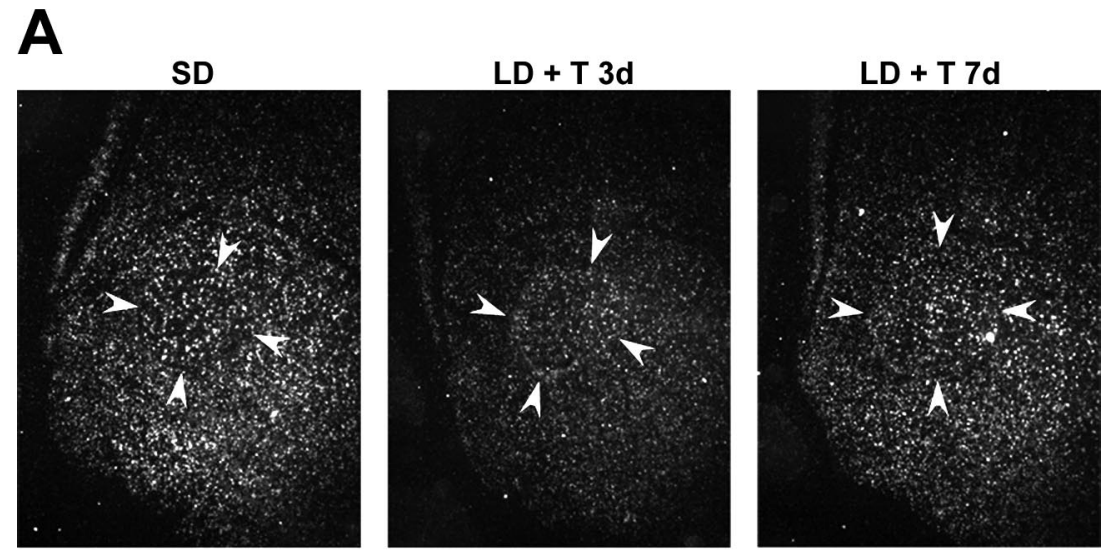

B

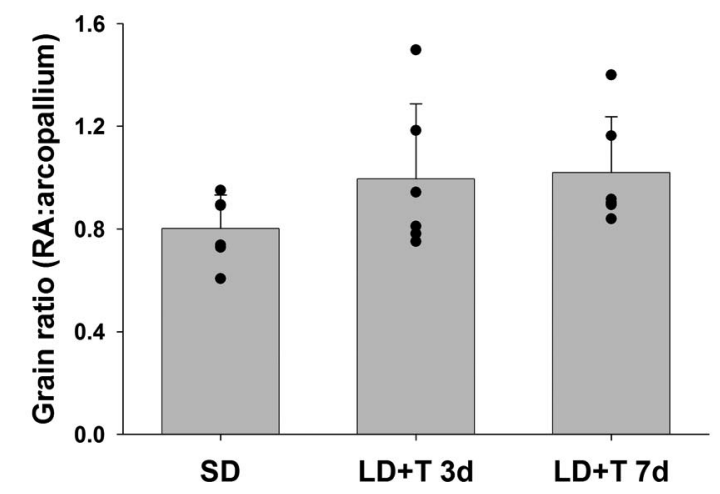

Figure 2. Dark-field photomicrograph $(\boldsymbol{A})$ and quantitative analysis $(\boldsymbol{B})$ of TrkB mRNA expression in RA in the different treatment groups. Arrows delineate the borders of RA. Data in $\boldsymbol{B}$ are expressed as a ratio of the grain density within the song nucleus versus the surrounding pallial region. Bars are group means \pm SEM, and each point represents one bird.

measurements on the side ipsilateral to the infusion versus the uninfused contralateral side for Experiment 2.

For Experiment 2a, we used two-way repeated measures ANOVAs to compare measurements on the ipsilateral versus the contralateral sides in HVC and RA of vehicle control birds with those of birds exposed to different doses of BDNF. For Experiment 2b, we used a two-way repeated measures ANOVA to compare measurements on the ipsilateral versus the contralateral side in RA of vehicle control birds with those of birds exposed to TrkB\&C-Fc, TrkB-Fc alone, and TrkC-Fc alone.

The $\alpha$ level for significance was set at $p=0.05$. All statistical tests were performed in SigmaStat (Systat). We used Tukey's HSD test for post hoc comparisons when the main factor was significant.

\section{Results}

Experiment 1: BDNF and TrkB gene expression in the song control system

We investigated the transcription profile of BDNF in HVC, RA, and Area $\mathrm{X}$ in captive white-crowned sparrows exposed to breeding versus nonbreeding conditions. We also looked at levels of mRNA for TrkB, the main receptor for BDNF, in RA.

\section{Experiment 1a: BDNF mRNA}

Plasma T levels were below the detection limit $(0.2 \mathrm{ng} / \mathrm{ml})$ in all SD birds. T levels in the LD+T $3 \mathrm{~d}$ group were $23.55 \pm 2.01 \mathrm{ng} / \mathrm{ml}$ (mean \pm SEM). T levels in the LD $+\mathrm{T} 7 \mathrm{~d}$ group were $27.70 \pm 7.68$ $\mathrm{ng} / \mathrm{ml}$. T levels in the LD-gonx group were $0.64 \pm 0.34 \mathrm{ng} / \mathrm{ml}$. The mean levels in the T-implanted groups were at the high end of reported levels in wild breeding birds, whereas the levels in the LD-gonx group were well below reported levels in wild breeding birds (Wingfield and Farner, 1978; Wingfield and Moore, 1987; J. C. Wingfield, unpublished observation).

BDNF mRNA was expressed in HVC (Fig. $1 A$ ) and was upregulated by LD and $\mathrm{T}$ (Table 1, Fig. 1C). Seven days of treatment with $\mathrm{LD}+\mathrm{T}$ significantly increased grain density ratio over SD controls. LDgonx birds and $\mathrm{LD}+\mathrm{T} 3 \mathrm{~d}$ birds had intermediate grain density ratios. Although it is possible that grain ratio differences could be driven by differences in the nidopallium control region, the only group difference we found in the nidopallium was a decrease in grain density in the LD-gonx group compared with the other groups ( $p=0.02)$ (supplemental Fig. S2a, available at www.jneurosci.org as supplemental material). Thus, the main effect of upregulation in the $\mathrm{LD}+\mathrm{T} 7 \mathrm{~d}$ group is driven by increased expression in HVC.

HVC grain density ratios across groups correlated positively with plasma T levels $(r=0.48 ; p=0.018)$. There were no significant correlations between HVC grain density ratio and $\mathrm{T}$ level within the $\mathrm{SD}$ gonx and LD-gonx groups, as T levels were undetectable in these birds. There was no correlation between HVC grain density ratio and $\mathrm{T}$ level within the $\mathrm{LD}+\mathrm{T} 7 \mathrm{~d}$ group. There was a negative correlation between HVC grain density ratio and $T$ level within the $\mathrm{LD}+\mathrm{T} 3 \mathrm{~d}$ group, but this effect was driven by one bird with below average $\mathrm{T}$ (but still well within breeding range) and the highest mRNA expression.

In most birds, BDNF mRNA was not strongly expressed in RA compared with surrounding arcopallium (Fig. 1B), and levels were not significantly affected by exposure to LD and T (Table 1 , Fig. $1 D$ ). Grain densities in the arcopallium were not significantly different across groups ( $p=0.76$ ) (supplemental Fig. S2 $b$, available at www.jneurosci.org as supplemental material). We did observe high levels of BDNF mRNA in two birds in the LD+T 3d group (Fig. 1D); although the levels were high in these birds, we did not exclude them from the analyses.

RA grain density ratios across groups did not significantly correlate with plasma T levels $(r=0.35 ; p=0.12)$. There were no significant correlations between RA grain density and T level within the SD-gonx and LD-gonx groups.

We did not observe any labeling for BDNF mRNA in Area X, nor elsewhere in the striatum, in any bird (supplemental Fig. S3, available at www.jneurosci.org as supplemental material).

Birds in the SD-gonx, $\mathrm{LD}+\mathrm{T} 3 \mathrm{~d}$, and LD-gonx groups did not sing during any recording session. Five of six birds in the $\mathrm{LD}+\mathrm{T}$ $7 \mathrm{~d}$ group sang at least one song during the last $4 \mathrm{~d}$ of recording (range: 1-20 songs/h), but only one bird sang during multiple sessions, and only three sang during the final pre-killing session (range: $9-19$ songs/h). Neither overall song rate nor total number of songs produced during the final session was correlated with BDNF mRNA levels in HVC $(r=-0.454 ; p=0.37$ for overall rate; $r=-0.509 ; p=0.30$ for song number $)$ or RA $(r=-0.128$; $p=0.81$ for overall rate; $r=0.543 ; p=0.27$ for song number). 
Table 2. RA neuronal attributes across hemispheres after infusion with BDNF, comparison among doses (mean \pm SEM)

\begin{tabular}{|c|c|c|c|c|c|c|c|c|c|c|}
\hline & \multirow[b]{3}{*}{ Vehicle controls } & \multirow{3}{*}{$\begin{array}{l}\text { BDNF } 0.67 \\
\mathrm{mg} / \mathrm{ml}\end{array}$} & \multirow{3}{*}{$\begin{array}{l}\text { BDNF } 1.0 \\
\mathrm{mg} / \mathrm{ml}\end{array}$} & \multirow[b]{3}{*}{ BDNF $1.5 \mathrm{mg} / \mathrm{ml}$} & \multicolumn{6}{|c|}{ Two-way repeated-measures ANOVA } \\
\hline & & & & & \multicolumn{2}{|c|}{ Treatment } & \multicolumn{2}{|l|}{ Side } & \multicolumn{2}{|c|}{ Interaction } \\
\hline & & & & & $F$ & $p$ & $F$ & $p$ & $F$ & $p$ \\
\hline Somatic area $\left(\mu \mathrm{m}^{2}\right)$ & & & & & 3.92 & 0.037 & 4.15 & 0.064 & 9.991 & 0.001 \\
\hline Ipsilateral & $101.37 \pm 6.56$ & $128.94 \pm 3.22$ & $108.44 \pm 6.83$ & $132.95 \pm 10.59$ & & & & & & \\
\hline Contralateral & $103.72 \pm 4.61$ & $138.59 \pm 1.71$ & $101.04 \pm 7.60$ & $111.63 \pm 9.16$ & & & & & & \\
\hline Density (neurons $/ \mathrm{mm}^{3}$ ) & & & & & 0.839 & 0.498 & 10.23 & 0.008 & 6.023 & 0.01 \\
\hline Ipsilateral & $\begin{array}{l}6.07 \times 10^{4} \pm \\
5.26 \times 10^{3}\end{array}$ & $\begin{array}{l}4.83 \times 10^{4} \pm \\
2.41 \times 10^{3}\end{array}$ & $\begin{array}{l}5.06 \times 10^{4} \pm \\
5.82 \times 10^{3}\end{array}$ & $\begin{array}{l}5.12 \times 10^{4} \pm \\
3.70 \times 10^{3}\end{array}$ & & & & & & \\
\hline Contralateral & $\begin{array}{l}5.94 \times 10^{4} \pm \\
5.34 \times 10^{3}\end{array}$ & $\begin{array}{l}4.86 \times 10^{4} \pm \\
4.44 \times 10^{3}\end{array}$ & $\begin{array}{l}5.55 \times 10^{4} \pm \\
5.46 \times 10^{3}\end{array}$ & $\begin{array}{l}6.43 \times 10^{4} \pm \\
6.86 \times 10^{3}\end{array}$ & & & & & & \\
\hline Neuron number & & & & & 1.934 & 0.18 & 0.144 & 0.71 & 0.755 & 0.54 \\
\hline Ipsilateral & $\begin{array}{l}1.40 \times 10^{4} \pm \\
0.61 \times 10^{3}\end{array}$ & $\begin{array}{l}1.70 \times 10^{4} \pm \\
0.20 \times 10^{3}\end{array}$ & $\begin{array}{l}1.33 \times 10^{4} \pm \\
1.60 \times 10^{3}\end{array}$ & $\begin{array}{l}1.33 \times 10^{4} \pm \\
1.50 \times 10^{3}\end{array}$ & & & & & & \\
\hline Contralateral & $\begin{array}{l}1.38 \times 10^{4} \pm \\
0.53 \times 10^{3}\end{array}$ & $\begin{array}{l}1.73 \times 10^{4} \pm \\
1.71 \times 10^{3}\end{array}$ & $\begin{array}{l}1.26 \times 10^{4} \pm \\
0.41 \times 10^{3}\end{array}$ & $\begin{array}{l}1.49 \times 10^{4} \pm \\
1.82 \times 10^{3}\end{array}$ & & & & & & \\
\hline
\end{tabular}

The bird that sang the most had a low level of BDNF mRNA expression in HVC.

\section{Experiment 1b: TrkB mRNA in RA}

We observed TrkB mRNA expression in RA and in the surrounding arcopallium (Fig. $2 \mathrm{~A}$ ). Grain density ratios did not change significantly with exposure to LD and T (Table 1, Fig. $2 B$ ). Qualitatively, TrkB mRNA was expressed widely throughout the telencephalon, including in HVC and Area X.

\section{Experiment 2: Local manipulation of BDNF levels in RA}

We tested whether a prolonged increase in BDNF protein levels in RA in nonbreeding condition birds would lead to morphological changes similar to those seen in response to LD photoperiod and systemic testosterone treatment $(\mathrm{LD}+\mathrm{T})$. We also locally blocked the actions of BDNF and/or NT-3 to test whether this would block the growth of RA neurons normally induced by $\mathrm{LD}+\mathrm{T}$ exposure. We accomplished this blockade by interfering with the binding of the ligands to their receptors using a fusion protein that links the Trk receptor with the Fc portion of the human IgG molecule (TrkB-Fc and TrkC-Fc; Cabelli et al., 1997; Xu et al., 2001; Rex et al., 2006).

\section{Experiment 2a: Confirmation of BDNF infusion of RA}

We examined immunolabeled sections in each brain to confirm that hr-BDNF was located in RA. One bird showed very little labeling, and had a large amount $(>30 \mu \mathrm{l})$ of BDNF remaining in the osmotic pump after sacrifice, implying that there was an obstruction in the cannula or tubing that prevented release of BDNF. Data from this bird were removed from the analyses. In all other birds at least one-half of RA was labeled on the infused side, with essentially no staining on the noninfused side (supplemental Fig. S4a,b, available at www.jneurosci.org as supplemental material).

\section{BDNF infusion promoted changes in RA somatic area and density}

BDNF infusion increased soma sizes in RA in a dose-dependent manner in birds maintained on SD (Table 2; Fig. 3A; supplemental Fig. S5, available at www.jneurosci.org as supplemental material). Our analysis showed a significant effect of treatment and a significant interaction between side and treatment. Post hoc pairwise comparisons showed that only the highest BDNF dose yielded a significant increase in RA somatic area on the ipsilateral side compared with the contralateral side. This increase is similar to the increase seen in GWCS exposed to LD and T (Tramontin et al., 2000).

Intracerebral BDNF infusion decreased neuronal density in RA in a dose-dependent manner (Table 2; Fig. 3B; supplemental Fig. S6, available at www.jneurosci.org as supplemental material). Our analysis showed a significant effect of hemisphere, with lower densities on the ipsilateral side across treatment groups, and a significant interaction between treatment and hemisphere. Post hoc pairwise comparisons confirmed a significantly lower neuronal density on the ipsilateral side compared with the contralateral side only in high-dose BDNF birds, although there was a similar trend in the $1 \mathrm{mg} / \mathrm{ml}$ group. Neuron number in RA did not differ across treatment groups (Table 2). BDNF infusion had no effect on RA volume (Fig. 3C).

\section{BDNF infusion near RA had no effect on HVC}

Infusion of BDNF at the highest dose near RA for 2 weeks had no effect on the volume of the afferent nucleus HVC (Table 3). Infusion of the highest dose $(1.5 \mathrm{mg} / \mathrm{ml})$ of BDNF did not significantly increase the somatic area of ipsilateral HVC neurons (Table 3), though there was a trend in this direction (Fig. 4A; supplemental S7, available at www.jneurosci.org as supplemental material). Neuronal density in HVC did not differ significantly between vehicle controls and high-dose BDNF birds, although there was a significant main effect of side across doses (Table 3). Once again we observed a trend toward a decrease in cell density on the infused side in high-dose BDNF birds (Fig. $4 \mathrm{~B}$; supplemental Fig. S7, available at www.jneurosci.org as supplemental material)

\section{Infusion effects were specific to BDNF}

To determine whether the effects described above were specific to BDNF, we infused NGF $(1.5 \mathrm{mg} \cdot \mathrm{ml})$ into RA in 2 birds, using the same methods as for the BDNF infusions. We saw no consistent effect of NGF infusion on RA neuronal somatic area (ipsilateral, 89.16 and $99.38 \mu \mathrm{m}^{2}$; contralateral, 88.46 and $91.98 \mu \mathrm{m}^{2}$, respectively) or volume (ipsilateral, 0.199 and $0.194 \mathrm{~mm}^{3}$; contralateral, 0.194 and $0.199 \mathrm{~mm}^{3}$, respectively) in these birds.

\section{Experiment 2b: Confirmation of Trk-Fc infusion of RA}

We examined immunolabeled sections in each Trk-Fc-infused brain to confirm that the antigen was located in RA as outlined in adjacent Nissl-stained sections from the infused hemisphere, 
A

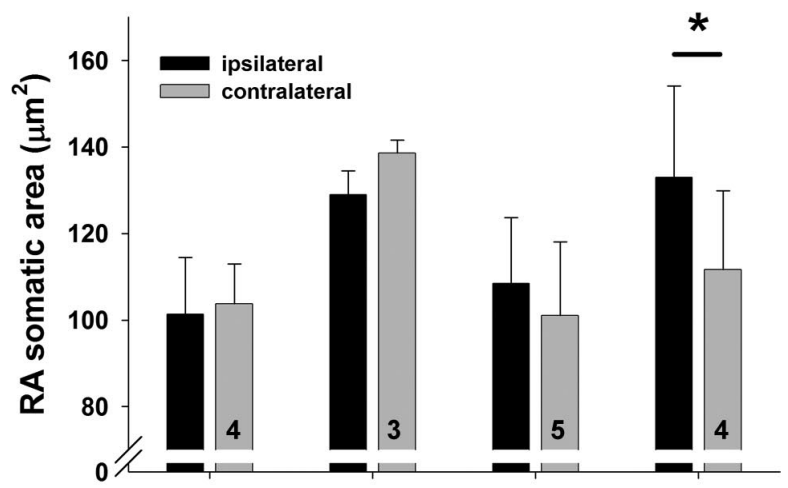

B
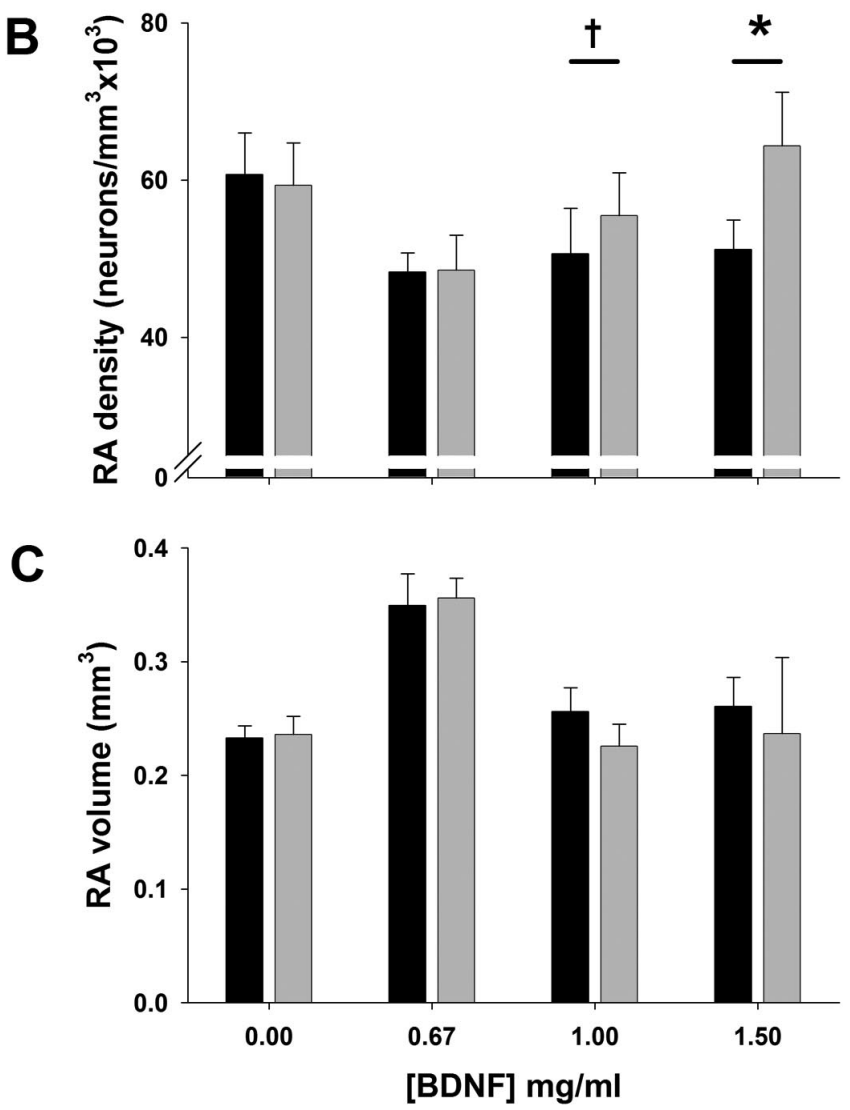

Figure 3. Comparison of RA somatic area $(\boldsymbol{A})$, neuronal density $(\boldsymbol{B})$, and volume $(\boldsymbol{C})$ in birds infused with one of four concentrations of BDNF near RA on one side of the brain. Bars are group means \pm SEM; numbers inside bars indicate number of birds in each group (each number refers also to adjoining bar from opposite hemisphere). Value of $p$ from Tukey's HSD, comparison between ipsilateral and contralateral side. Symbols above bars represent differences between ipsilateral and contralateral sides (Tukey's HSD); ${ }^{*} p<0.001 ;{ }^{\dagger} p=0.058$.

with no labeling on the noninfused side (supplemental Fig. $54 c, d$, available at www.jneurosci.org as supplemental material). Two birds showed very little labeling, and also had $>30 \mu$ l of Trk-Fc remaining in the pump at the end of the experiment, implying a blockage in the cannula/pump system. Data from these birds were not included in the analyses.

TrkB\&C-Fc reduced the somatic area increase in RA Infusion of the combined TrkB\&C-Fc resulted in significantly smaller somatic areas of RA neurons on the ipsilateral side compared with the contralateral side in birds exposed to $\mathrm{LD}+\mathrm{T}$ (Table 4; Fig. 5A; supplemental Fig. S8, available at www. jneurosci.org as supplemental material). The interaction effect in the two-way ANOVA was marginally significant and post hoc tests demonstrated that the difference in somatic area across hemispheres in the TrkB\&C-FC group $(p<0.001)$ accounted for the main effect of hemisphere, whereas other treatment groups showed no significant difference across hemispheres $(p \geq 0.1)$.

Our analysis showed a similar effect of hemisphere on neuronal density across treatment groups, with higher density on the ipsilateral side (Fig. 5B; supplemental Fig. S8, available at www. jneurosci.org as supplemental material). Again, post hoc tests showed an effect of hemisphere in the TrkB\&C-Fc group ( $p=$ $0.059)$, but we saw no effect of hemisphere in the other groups $(p>0.1)$. Note that the slight difference in mean neuronal density across sides in the vehicle controls in this study is opposite to what we saw in controls in the BDNF infusion study. We also saw a main effect of treatment on neuronal density, with saline birds showing higher density than TrkB-Fc or TrkB/C-Fc birds, regardless of hemisphere $(p=0.04)$. Given that the test result is marginally significant and has low power $(0.43)$, it is difficult to draw any firm conclusion from this difference. We believe that this effect reflects sampling variation and perhaps differences in tissue processing. We cannot, however, exclude the possibility that there is some systemic effect of TrkB/C-Fc infusion on neuronal density.

\section{Discussion}

We showed that BDNF and TrkB are present in the song system in white-crowned sparrows, that BDNF expression in HVC increases in response to seasonal cues, that BDNF is sufficient to promote breeding season-like growth in RA, and that neurotrophins in RA are necessary for the breeding-like increase in somatic area. These results indicate that endogenous neurotrophins play an important role in the seasonal plasticity of the song control system.

Our finding that $\mathrm{T}$ increased BDNF mRNA expression in sparrow $\mathrm{HVC}$ is consistent with previous reports. BDNF protein levels in HVC increase in adult female canaries treated with $\mathrm{T}$ (Rasika et al., 1999). This increase is blocked by inhibition of estrogen synthesis, suggesting that BDNF transcription may be regulated by aromatization of $\mathrm{T}$ to $\mathrm{E}_{2}$ (Fusani et al., 2003). T and/or $\mathrm{E}_{2}$ may indirectly increase BDNF mRNA expression in $\mathrm{HVC}$ by acting on hypothalamic regions to increase song production and thereby increase neural activity in the song system (Ball et al., 2004). BDNF expression in HVC correlates positively with song rate in male canaries ( $\mathrm{Li}$ et al., 2000). We did not see a correlation between song rate and BDNF mRNA levels, and our data show that $\mathrm{T}$ can upregulate BDNF mRNA in the absence of increased song rates. $\mathrm{LD}+\mathrm{T}$ promotes equivalent growth of the song system in deafened birds compared with hearing birds that sing eight times more often (Brenowitz et al., 2007), intracerebral $\mathrm{T}$ can promote song system growth in birds that do not sing (Brenowitz and Lent, 2002), and song stereotypy continues to increase in birds shifted to LD $+\mathrm{T}$ after $\mathrm{HVC}$ has reached its full breeding-condition size (Tramontin et al., 2000). These results combined with our findings suggest that T-mediated upregulation of BDNF in HVC could induce growth of the song system without acting through an increase in song behavior.

T could increase BDNF expression via aromatization to estradiol. The BDNF gene contains a putative estrogen response element, and BDNF expression is upregulated by steroid hormones in many parts of the nervous system (Sohrabji et al., 1995; Scharfman and Maclusky, 2005). BDNF expression can also be upregulated by increased neural activity (Shieh and Ghosh, 1999; 
Table 3. HVC attributes across hemispheres, comparison between vehicle controls and high-dose BDNF birds (mean \pm SEM)

\begin{tabular}{|c|c|c|c|c|c|c|c|c|c|c|}
\hline & \multicolumn{2}{|l|}{ Vehicle controls } & \multicolumn{2}{|l|}{ BDNF $1.5 \mathrm{mg} / \mathrm{ml}$} & \multicolumn{2}{|c|}{ Treatment } & \multicolumn{2}{|c|}{ Hemisphere } & \multicolumn{2}{|c|}{ Interaction } \\
\hline & Ipsilateral & Contralateral & Ipsilateral & Contralateral & $F$ & $p$ & $F$ & $p$ & $F$ & $p$ \\
\hline Somatic area $\left(\mu \mathrm{m}^{2}\right)$ & $45.39 \pm 2.21$ & $45.08 \pm 2.98$ & $49.70 \pm 5.58$ & $41.50 \pm 6.13$ & 0.0036 & 0.95 & 4.24 & 0.085 & 3.65 & 0.10 \\
\hline Density (neurons $/ \mathrm{mm}^{3}$ ) & $\begin{array}{l}2.22 \times 10^{5} \pm \\
1.49 \times 10^{4}\end{array}$ & $\begin{array}{l}2.47 \times 10^{5} \pm \\
2.14 \times 10^{4}\end{array}$ & $\begin{array}{l}2.49 \times 10^{5} \pm \\
3.79 \times 10^{4}\end{array}$ & $\begin{array}{l}2.86 \times 10^{5} \pm \\
2.82 \times 10^{4}\end{array}$ & 0.82 & 0.40 & 8.08 & 0.029 & 0.26 & 0.63 \\
\hline Volume $\left(\mathrm{mm}^{3}\right)$ & $0.51 \pm 0.06$ & $0.47 \pm 0.03$ & $0.54 \pm 0.07$ & $0.50 \pm 0.09$ & 0.113 & 0.75 & 3.467 & 0.11 & 0.019 & 0.89 \\
\hline
\end{tabular}

\section{A}
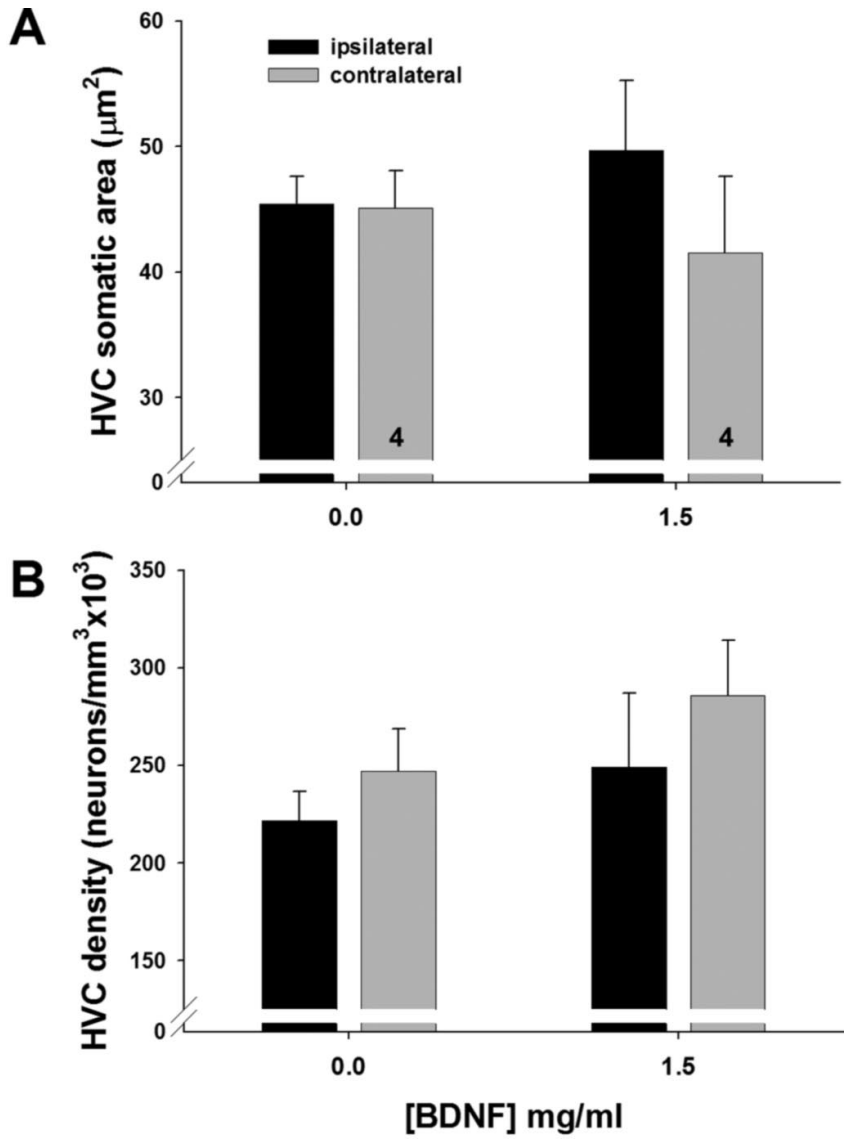

Figure 4. Comparison of HVC somatic area $(\boldsymbol{A})$ and neuronal density $(\boldsymbol{B})$ across hemispheres in birds infused with vehicle or the highest dose of BDNF. Bars are group means \pm SEM; numbers inside bars indicate number of birds in each group.

Schinder and Poo, 2000). Metabolites of T can modulate GABAA receptors, either by direct interaction with the receptors (Majewska, 1992) or by changing receptor subunit composition (Nunez and McCarthy, 2008), either of which could enhance excitability in HVC. Determining the site of action of steroids in the regulation of BDNF expression is a productive direction for future research.

We saw little or no expression of BDNF mRNA in RA in most birds, and in Area $\mathrm{X}$ in all birds. These observations suggest that effects of BDNF on the growth of HVC's downstream targets are mediated largely by anterograde axonal transport from HVC. It is interesting that two birds showed high levels of BDNF expression in RA. These two birds also had the highest levels of expression in HVC, which could indicate a positive feedback loop between RA-projecting HVC neurons and their targets in these birds. For example, BDNF can act via the mitogen-activated protein kinase (MAPK) signaling pathway to increase phosphorylation of cAMP response element-binding protein (CREB) (Lonze and Ginty, 2002), and phosphorylated CREB acts as a transcription factor that can increase expression of BDNF (Ivanova et al., 2001; West et al., 2001). It is possible that there is a transient increase in BDNF expression in RA in response to $\mathrm{LD}$ and $\mathrm{T}$, and that we happened to catch it at the right time in those two birds. We attempted to replicate these findings by running a BDNF in situ on some sections containing RA from birds in Experiment 2; however, we failed to see comparably high levels of labeling in any sections.

Our finding that TrkB expression, at least in RA, is not seasonally regulated is consistent with previous research by Chen and colleagues (2005), showing that TrkB mRNA is widely expressed in the zebra finch telencephalon and suggesting that a sex difference in expression levels may be genetically rather than hormonally regulated. Given that TrkB mRNA appears to be constitutively expressed throughout the telencephalon in GWCS, seasonal regulation of its ligand BDNF likely underlies the induction and/or modulation of neural plasticity in the song system.

Our findings suggest that BDNF plays a role in the seasonal growth of the song system. The presence of BDNF mRNA in HVC, its absence in RA and Area X, and the presence of the TrkB receptor in the downstream nuclei suggest that BDNF is transported anterogradely from HVC. Infusing recombinant BDNF into RA in non-breeding condition birds mimicked the effects of breeding physiology on neuronal size and density in RA. BDNF, but not NGF, increased RA neuronal size and decreased neuronal density without inducing significant changes in HVC. These changes suggest that BDNF acts directly on RA neurons to induce breeding season-like growth of this nucleus. In addition, the lack of effect of NGF suggests that BDNF acts primarily on the TrkB receptor rather than the 75 receptor, which can also be activated by NGF (Reichardt, 2006).

The trends toward a neuronal size increase and cell density decrease in HVC of the birds infused in RA with BDNF suggest that there may have been some retrograde transport of the infused BDNF. It is possible that retrogradely transported BDNF within HVC had an indirect effect via some other growth factor or a change in HVC activity levels to cause the changes seen in RA. The weakness of the changes seen in HVC compared with those seen in RA, however, argues against this possibility.

The lack of a change in RA volume might seem surprising given the changes in neuronal density. Tramontin et al. (2000), however, showed that while somatic area was fully increased in RA by $7 \mathrm{~d}$ of LD and T treatment, the overall volume did not change significantly until after $20 \mathrm{~d}$ of treatment. Neuronal density was at an intermediate level at $7 \mathrm{~d}$. It is possible that the 14-day BDNF infusion was not long enough to increase the volume of RA. Changes in neuronal density and size appear to precede and contribute considerably to changes in nuclear volume (Tramontin and Brenowitz, 2000).

Infusing TrkB\&C-Fc into RA inhibited the trophic effects of LDs and $\mathrm{T}$ on somatic area and neuronal density in RA. We did not see a significant effect of infusing TrkB-Fc or TrkC-Fc alone into RA. It is possible that BDNF and NT-3 play complementary or redundant roles in the changes in RA somatic area in response 
Table 4. RA neuronal attributes across hemispheres after infusion with Trk-Fc fusion proteins, comparison among treatment groups (mean \pm SEM)

\begin{tabular}{|c|c|c|c|c|c|c|c|c|c|c|}
\hline & \multirow[b]{3}{*}{ Saline } & \multirow[b]{3}{*}{ TrkB-FC } & \multirow[b]{3}{*}{ TrkC-Fc } & \multirow[b]{3}{*}{ TrkB\&C-Fc } & \multicolumn{6}{|c|}{ Two-way repeated-measures ANOVA } \\
\hline & & & & & \multicolumn{2}{|c|}{ Treatment } & \multicolumn{2}{|l|}{ Side } & \multicolumn{2}{|c|}{ Interaction } \\
\hline & & & & & $F$ & $p$ & $F$ & $p$ & $F$ & $p$ \\
\hline Ipsilateral & $112.36 \pm 10.67$ & $143.05 \pm 11.04$ & $103.46 \pm 5.93$ & $129.75 \pm 14.88$ & 1.466 & 0.28 & 9.70 & 0.01 & 3.36 & 0.059 \\
\hline Contralateral & $116.26 \pm 7.45$ & $142.94 \pm 1.30$ & $114.88 \pm 9.37$ & $151.64 \pm 16.0$ & & & & & & \\
\hline \multicolumn{11}{|c|}{ Density (neurons/mm³) } \\
\hline Contralateral & $\begin{array}{l}6.44 \times 10^{4} \pm \\
5.73 \times 10^{3}\end{array}$ & $\begin{array}{l}4.00 \times 10^{4} \pm \\
4.60 \times 10^{3}\end{array}$ & $\begin{array}{l}4.38 \times 10^{4} \pm \\
6.44 \times 10^{3}\end{array}$ & $\begin{array}{l}3.93 \times 10^{4} \pm \\
3.1 \times 10^{3}\end{array}$ & & & & & & \\
\hline
\end{tabular}

A
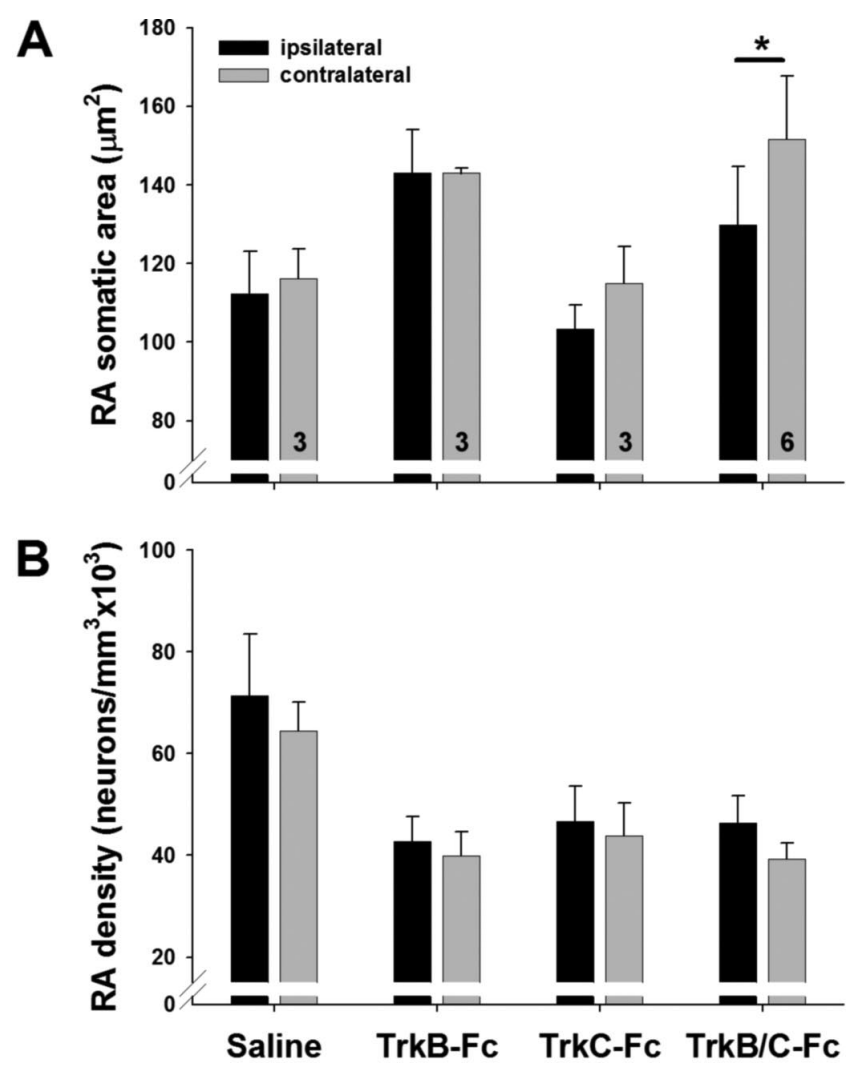

Figure 5. Comparison of RA somatic area $(\boldsymbol{A})$ and neuronal density $(\boldsymbol{B})$ across hemispheres in birds infused with saline, TrkB-Fc alone, TrkC-Fc alone, or TrkB\&C-Fc. Bars are group means \pm SEM; numbers inside bars indicate number of birds in each group. ${ }^{*} p=0.059$ (Tukey's HSD), comparison between ipsilateral and contralateral side.

to seasonal cues, and the activity of either neurotrophin may be able to compensate for a decrease in the activity of the other. We focused on BDNF in this study because of previous research showing that it is regulated by steroids in the song system as well as other systems. We found no reports of sex steroid regulation of NT-3, although stress and glucocorticoids can increase NT-3 levels in the hippocampus (Smith, 1996). It will be important, however, to investigate the levels of NT-3 and TrkC in the song nuclei of breeding and nonbreeding condition birds to better determine their role in seasonal plasticity. Preliminary data from a cDNA microarray study show that both BDNF precursor and NT-3 precursor had significantly higher expression in HVC tissue taken from LD $+\mathrm{T}$ birds compared with SD birds (our unpublished data).

It is also possible that NT-4, another neurotrophin that binds with high affinity to the $\operatorname{TrkB}$ receptor, plays a role in seasonal plasticity in the song system. NT-4 and BDNF often overlap in their effects, but not always (Lodovichi et al., 2000), which may be due to different receptor binding properties (Minichiello et al., 1998). It would be worthwhile to investigate NT-4 expression in the song system to determine whether there is any overlap with BDNF and/or TrkB.

It is unclear why we found a higher neuronal density on the ipsilateral side across treatment groups in this experiment, although it is possible that local inflammation in response to the cannula played a role. Such an effect would presumably also occur in our BDNF infusion study, and yet we saw a decrease in density on the ipsilateral side, suggesting that the effect of BDNF on neuron density in RA transcends any local damage-induced increase in density.

There are several possible mechanisms of BDNF's effects on the growth of RA. BDNF acting through TrkB receptors can activate the MAPK/ERK (MAPK/extracellular signal-regulated kinase) and PI3 (phosphatidylinositol 3)-kinase-Akt pathways, which are known to play a role in structural plasticity of neurons (Wu et al., 2001; Vaillant et al., 2002). Activation of these pathways also promotes cAMP response element-binding protein phosphorylation, which regulates the transcription of many plasticity-related genes (Lonze and Ginty, 2002). Alternatively, TrkB can activate PLC- $\gamma$ (phospholipase-C- $\gamma$ ) to increase intracellular $\mathrm{Ca}^{2+}$ levels, thereby activating $\mathrm{Ca}^{2+} /$ calmodulindependent kinases II and IV (CaMKII; CaMKIV), which regulate dendritic growth and spine formation (Dijkhuizen and Ghosh, 2005). In the adult zebra finch, injection of BDNF into RA increases the density of synaptic boutons of HVC axons on RA neurons (Kittelberger and Mooney, 2005). We did not measure dendritic branching or spine density in this study, but given the seasonal changes in these attributes seen in other songbirds (Hill and DeVoogd, 1991), as well as the effects of BDNF on dendrites in other systems, such changes may have occurred in our BDNFinfused birds as well.

The role of endogenous neurotrophins in seasonal growth of RA is still under investigation. We hypothesize that BDNF serves as a link between the action of circulating steroid hormones on HVC and the changes in RA, X, and song behavior that occur in response to seasonal cues. Although we have shown that BDNF mRNA increases in HVC in response to seasonal-like cues, it will be important to determine whether endogenous levels of BDNF (and/or NT-3) protein increase in RA under breeding-like conditions. If BDNF protein levels do increase seasonally in RA, then the increase may be due to local production and/or anterograde transport from HVC and/or from the lateral magnocellular nucleus of the anterior nidopallium (IMAN), both of which are 
afferent to RA. Additional studies are needed to understand the detailed mechanisms, but the present study suggests that neurotrophins play a role in the seasonal plasticity of the song system and provides insight into the importance of these growth factors in a model of systems-level changes in the neural structures that control a learned behavior.

\section{References}

Ball GF, Auger CJ, Bernard DJ, Charlier TD, Sartor JJ, Riters LV, Balthazart J (2004) Seasonal plasticity in the song control system: multiple brain sites of steroid hormone action and the importance of variation in song behavior. Ann NY Acad Sci 1016:586-610.

Binder DK, Scharfman HE (2004) Brain-derived neurotrophic factor. Growth Factors 22:123-131.

Brenowitz EA (2004) Plasticity of the adult avian song control system. Ann NY Acad Sci 1016:560-585.

Brenowitz EA, Lent K (2002) Act locally and think globally: intracerebral testosterone implants induce seasonal-like growth of adult avian song control circuits. Proc Natl Acad Sci U S A 99:12421-12426.

Brenowitz EA, Lent K, Kroodsma DE (1995) Brain space for learned song in birds develops independently of song learning. J Neurosci 15:6281-6286.

Brenowitz EA, Lent K, Rubel EW (2007) Auditory feedback and song production do not regulate seasonal growth of song control circuits in adult white-crowned sparrows. J Neurosci 27:6810-6814.

Cabelli RJ, Shelton DL, Segal RA, Shatz CJ (1997) Blockade of endogenous ligands of trkB inhibits formation of ocular dominance columns. Neuron 19:63-76.

Chen X, Agate RJ, Itoh Y, Arnold AP (2005) Sexually dimorphic expression of trkB, a Z-linked gene, in early posthatch zebra finch brain. Proc Natl Acad Sci U S A 102:7730-7735.

Dijkhuizen PA, Ghosh A (2005) Regulation of dendritic growth by calcium and neurotrophin signaling. Prog Brain Res 147:17-27.

Dittrich F, Feng Y, Metzdorf R, Gahr M (1999) Estrogen-inducible, sexspecific expression of brain-derived neurotrophic factor mRNA in a forebrain song control nucleus of the juvenile zebra finch. Proc Natl Acad Sci U S A 96:8241-8246.

Fusani L, Metzdorf R, Hutchison JB, Gahr M (2003) Aromatase inhibition affects testosterone-induced masculinization of song and the neural song system in female canaries. J Neurobiol 54:370-379.

Galuske RA, Kim DS, Singer W (1999) The role of neurotrophins in developmental cortical plasticity. Restor Neurol Neurosci 15:115-124.

Goldman SA, Nottebohm F (1983) Neuronal production, migration, and differentiation in a vocal control nucleus of the adult female canary brain. Proc Natl Acad Sci U S A 80:2390-2394.

Hill KM, DeVoogd TJ (1991) Altered daylength affects dendritic structure in a song-related brain region in red-winged blackbirds. Behav Neural Biol 56:240-250.

Ivanova T, Küppers E, Engele J, Beyer C (2001) Estrogen stimulates brainderived neurotrophic factor expression in embryonic mouse midbrain neurons through a membrane-mediated and calcium-dependent mechanism. J Neurosci Res 66:221-230.

Johnson F, Hohmann SE, DiStefano PS, Bottjer SW (1997) Neurotrophins suppress apoptosis induced by deafferentation of an avian motor-cortical region. J Neurosci 17:2101-2111.

Kittelberger JM, Mooney R (2005) Acute injections of brain-derived neurotrophic factor in a vocal premotor nucleus reversibly disrupt adult birdsong stability and trigger syllable deletion. J Neurobiol 62:406-424.

Kojima M, Takei N, Numakawa T, Ishikawa Y, Suzuki S, Matsumoto T, Katoh-Semba R, Nawa H, Hatanaka H (2001) Biological characterization and optical imaging of brain-derived neurotrophic factor-green fluorescent protein suggest an activity-dependent local release of brainderived neurotrophic factor in neurites of cultured hippocampal neurons. J Neurosci Res 64:1-10.

Lessmann V, Gottmann K, Malcangio M (2003) Neurotrophin secretion: current facts and future prospects. Prog Neurobiol 69:341-374.

Li XC, Jarvis ED, Alvarez-Borda B, Lim DA, Nottebohm F (2000) A relationship between behavior, neurotrophin expression, and new neuron survival [In Process Citation]. Proc Natl Acad Sci U S A 97:8584-8589.

Lodovichi C, Berardi N, Pizzorusso T, Maffei L (2000) Effects of neurotrophins on cortical plasticity: same or different? J Neurosci 20:2155-2165.

Lonze BE, Ginty DD (2002) Function and regulation of CREB family transcription factors in the nervous system. Neuron 35:605-623.
Lu L, Dempsey J, Liu SY, Bossert JM, Shaham Y (2004) A single infusion of brain-derived neurotrophic factor into the ventral tegmental area induces long-lasting potentiation of cocaine seeking after withdrawal. J Neurosci 24:1604-1611.

Majewska MD (1992) Neurosteroids: endogenous bimodal modulators of the GABAA receptor-mechanism of action and physiological significance. Prog Neurobiol 38:379-395.

Meitzen J, Perkel DJ, Brenowitz EA (2007a) Seasonal changes in intrinsic electrophysiological activity of song control neurons in wild song sparrows. J Comp Physiol A Neuroethol Sens Neural Behav Physiol 193:677-683.

Meitzen J, Moore IT, Lent K, Brenowitz EA, Perkel DJ (2007b) Steroid hormones act transsynaptically within the forebrain to regulate neuronal phenotype and song stereotypy. J Neurosci 27:12045-12057.

Minichiello L, Casagranda F, Tatche RS, Stucky CL, Postigo A, Lewin GR, Davies AM, Klein R (1998) Point mutation in trkB causes loss of NT4dependent neurons without major effects on diverse BDNF responses. Neuron 21:335-345.

Nunez JL, McCarthy MM (2008) Androgens predispose males to GABAAmediated excitotoxicity in the developing hippocampus. Exp Neurol 210:699-708

Patapoutian A, Reichardt LF (2001) Trk receptors: mediators of neurotrophin action. Curr Opin Neurobiol 11:272-280.

Quagliano A, Bottjer SW (2004) Localization of endogenous neurotrophins during the development of axonal projections from IMAN to RA in the zebra finch song system. Soc Neurosci Abstr 30:333.335.

Rasika S (1998) A steroid-neurotrophin pathway for the seasonal regulation of neuronal replacement in the adult canary brain. $\mathrm{PhD}$ thesis, Rockefeller University.

Rasika S, Alvarez-Buylla A, Nottebohm F (1999) BDNF mediates the effects of testosterone on the survival of new neurons in an adult brain. Neuron 22:53-62.

Reichardt LF (2006) Neurotrophin-regulated signalling pathways. Philos Trans R Soc Lond B Biol Sci 361:1545-1564.

Rex CS, Lauterborn JC, Lin CY, Kramár EA, Rogers GA, Gall CM, Lynch G (2006) Restoration of long-term potentiation in middle-aged hippocampus after induction of brain-derived neurotrophic factor. J Neurophysiol 96:677-685.

Scharfman HE, Maclusky NJ (2005) Similarities between actions of estrogen and BDNF in the hippocampus: coincidence or clue? Trends Neurosci 28:79-85.

Schinder AF, Poo M (2000) The neurotrophin hypothesis for synaptic plasticity. Trends Neurosci 23:639-645.

Schmidt MF, Ashmore RC, Vu ET (2004) Bilateral control and interhemispheric coordination in the avian song motor system. Ann N Y Acad Sci 1016:171-186.

Shelton DL, Sutherland J, Gripp J, Camerato T, Armanini MP, Phillips HS, Carroll K, Spencer SD, Levinson AD (1995) Human Trks - MolecularCloning, Tissue Distribution, and Expression of Extracellular Domain Immunoadhesins. J Neurosci 15:477-491.

Shieh PB, Ghosh A (1999) Molecular mechanisms underlying activitydependent regulation of BDNF expression. J Neurobiol 41:127-134.

Smith GT, Brenowitz EA, Wingfield JC, Baptista LF (1995) Seasonal changes in song nuclei and song behavior in Gambel's white-crowned sparrows. J Neurobiol 28:114-125.

Smith GT, Brenowitz EA, Wingfield JC (1997a) Seasonal changes in the size of the avian song control nucleus HVC defined by multiple histological markers. J Comp Neurol 381:253-261.

Smith GT, Brenowitz EA, Wingfield JC (1997b) Roles of photoperiod and testosterone in seasonal plasticity of the avian song control system. J Neurobiol 32:426-442.

Smith GT, Brenowitz EA, Beecher MD, Wingfield JC (1997c) Seasonal changes in testosterone, neural attributes of song control nuclei, and song structure in wild songbirds. J Neurosci 17:6001-6010.

Smith MA (1996) Hippocampal vulnerability to stress and aging: possible role of neurotrophic factors. Behav Brain Res 78:25-36.

Sohrabji F, Miranda RC, Toran-Allerand CD (1995) Identification of a putative estrogen response element in the gene encoding brain-derived neurotrophic factor. Proc Natl Acad Sci U S A 92:11110-11114.

Suthers RA (1997) Peripheral control and lateralization of birdsong. J Neurobiology 33:632-652. 
Thomas K, Davies A (2005) Neurotrophins: a ticket to ride for BDNF. Curr Biol 15:R262-R264.

Tramontin AD, Brenowitz EA (2000) Seasonal plasticity in the adult brain. Trends Neurosci 23:251-258.

Tramontin AD, Smith GT, Breuner CW, Brenowitz EA (1998) Seasonal plasticity and sexual dimorphism in the avian song control system: stereological measurement of neuron density and number. J Comp Neurol 396:186-192.

Tramontin AD, Hartman VN, Brenowitz EA (2000) Breeding conditions induce rapid and sequential growth in adult avian song control circuits: a model of seasonal plasticity in the brain. J Neurosci 20:854-861.

Tramontin AD, Perfito N, Wingfield JC, Brenowitz EA (2001) Seasonal growth of song control nuclei precedes seasonal reproductive development in wild adult song sparrows. Gen Comp Endocrinol 122:1-9.

Vaillant AR, Zanassi P, Walsh GS, Aumont A, Alonso A, Miller FD (2002) Signaling mechanisms underlying reversible, activity-dependent dendrite formation. Neuron 34:985-998.

von Bartheld CS, Fritzsch B (2006) Comparative analysis of neurotrophin receptors and ligands in vertebrate neurons: tools for evolutionary stability or changes in neural circuits? Brain Behav Evol 68:157-172.

von Bartheld CS, Wang X, Butowt R (2001) Anterograde axonal transport, transcytosis, and recycling of neurotrophic factors: the concept of trophic currencies in neural networks. Mol Neurobiol 24:1-28.
Wade J (2000) TrkB-like immunoreactivity in the song system of developing zebra finches. J Chem Neuroanat 19:33-39.

West AE, Chen WG, Dalva MB, Dolmetsch RE, Kornhauser JM, Shaywitz AJ, Takasu MA, Tao X, Greenberg ME (2001) Calcium regulation of neuronal gene expression. Proc Natl Acad Sci U S A 98:11024-11031.

Wild JM (1997) Neural pathways for the control of birdsong production. J Neurobiol 33:653-670.

Wingfield JC, Farner DS (1978) The annual cycle of plasma irLH and steroid hormones in feral populations of the white-crowned sparrow, Zonotrichia leucophrys gambelii. Biol Reprod 19:1046-1056.

Wingfield JC, Moore MC (1987) Hormonal, social, and environmental factors in the reproductive biology of free-living male birds. In: Psychobiology of reproductive behavior: an evolutionary perspective (Crews D, ed). Englewood Cliffs, NJ: Prentice-Hall.

Wu GY, Deisseroth K, Tsien RW (2001) Spaced stimuli stabilize MAPK pathway activation and its effects on dendritic morphology. Nat Neurosci 4:151-158.

Xu J, Gingras KM, Bengston L, Di Marco A, Forger NG (2001) Blockade of endogenous neurotrophic factors prevents the androgenic rescue of rat spinal motoneurons. J Neurosci 21:4366-4372.

Zweifel LS, Kuruvilla R, Ginty DD (2005) Functions and mechanisms of retrograde neurotrophin signalling. Nat Rev Neurosci 6:615-625. 